\title{
DA ADMINISTRAÇÃO PÚBLICA BUROCRÁTICA À GERENCIAL: O DESAFIO DA POLITIZAÇÃO DA BUROCRACIA NO PRESIDENCIALISMO DE COALIZÃO
}

\section{FROM BUROCRATIC PUBLIC ADMINISTRATION TO MANAGEMENT: THE CHALLENGE POLITIZATION OF BUROCRACY IN THE COALITION PRESIDENTIALISM}

\author{
Tiago Resende Botelho ${ }^{1}$ \\ Thaisa Maira Held ${ }^{2}$
}

Recebido em: 22/01/2021 Aceito em: 27/07/2021

trbotelho@hotmail.com thaisaheld@ufgd.edu.br
Resumo: O trabalho tem como objetivo compreender o percurso da administração pública indo da burocrática à gerencial e, consequentemente, apontar os desafios da politização da burocracia no presidencialismo de coalizão. Para tal, trilha-se o processo histórico de formação teórica da burocracia. Após, busca-se compreender a recepção brasileira da teoria burocrática e a tentativa de afastamento do patrimonialismo vigente. Em seguida, adentra-se à reforma gerencial da administração pública, procurando entender a relação com a burocracia no presidencialismo de coalizão nos mandatos de Fernando Henrique Cardoso, Luiz Inácio Lula da Silva, Dilma Vana Rousseff e Michel Temer. Para assim, analisar os desafios da politização da burocracia no presidencialismo de coalizão. Ao final da pesquisa, apura-se que a relação do sistema político com a burocracia no presidencialismo de coalizão é fortemente marcada tanto pelo incentivo institucional quanto pela formação histórica do país. A centralização do controle discricionário sobre cargos e orçamento pelo Poder Executivo transformou-se em reserva burocrática na construção da coalizão. Em contrapartida, membros de partidos e políticos eleitos disputam por espaços dentro da burocracia administrativa que vem se avolumando desde a redemocratização. Ainda que boa parte dos estudos avaliem que a politização da burocracia tem conseguido garantir o sucesso do presidencialismo de coalizão por meio dos índices de propostas e aprovações de projetos de lei pelo Poder Executivo, esta pesquisa entende que tal análise é apenas um dos índices de aferição. É preciso ir além, pois a proliferação de partidos para construção da maioria simples e maioria qualificada desde a redemocratização amplia a cada nova eleição e, portanto, demanda da estrutura burocrática mais ministérios e cargos para que se recepcione maior número de partidos. Assim, a pesquisa aponta a necessidade de maior performance das reformas administrativas e modernização da relação do presidencialismo de coalizão com a burocracia, os partidos políticos, seus lideres partidários e o Poder Legislativo.

Palavras-chave: administração pública. burocracia. reforma gerencial. presidencialismo de coalizão. politização..

\begin{abstract}
The objective of this work is to understand the course of public administration from bureaucratic to managerial and, consequently, to point out the challenges of the politicization of bureaucracy in coalition presidentialism. For this, the historical process of theoretical formation of the bureaucracy is traced. Afterwards, one tries to understand the Brazilian reception of bureaucratic theory and the attempt to move away from the current patrimonialism. He then approaches the management reform of the public administration, trying to understand the relationship with the bureaucracy in coalition presidentialism under the terms of Fernando Henrique Cardoso, Luiz Inácio Lula da Silva, Dilma Vana Rousseff and Michel Temer. In order to analyze the challenges of the politicization of bureaucracy in coalition presidentialism. At the end of the research, it is found that the relationship between the political system and the bureaucracy in coalition presidentialism is strongly marked by both the institutional incentive and the historical formation of the country. The centralization of discretionary control over positions and budget by the Executive Power has become a bureaucratic reserve in the construction of the coalition. On the other hand, party members and elected politicians vie for spaces within the administrative bureaucracy that has been increasing since
\end{abstract}

\footnotetext{
${ }^{1}$ Universidade Federal da Grande Dourados. Mato Grosso do Sul. Brasil.

2 Universidade Federal da Grande Dourados. Mato Grosso do Sul. Brasil.
} 
redemocratization. Although a good part of the studies evaluate that the politicization of the bureaucracy has managed to guarantee the success of the presidential coalition through the indexes of proposals and approvals of bills by the Executive Power, this research understands that this analysis is only one of the indexes of measurement. It is necessary to go beyond, since the proliferation of parties for the construction of the simple majority and qualified majority since redemocratization expands with each new election and therefore demands of the bureaucratic structure more ministries and positions so that more number of parties are received. Thus, the research points out the need for greater performance of the administrative reforms and modernization of the relationship of coalition presidentialism with the bureaucracy, political parties, their party leaders and the Legislative Branch

Keywords: public administration. bureaucracy. management reform. coalition presidentialism. Politicization.

\section{INTRODUÇÃO}

O estudo da burocracia pública e de sua relação com o sistema político é tema pouco aprofundado no Brasil. Esta realidade está intimamente ligada aos trezentos e vinte e dois anos de colonização (1500 - 1822) somados aos cento e oito anos de administração patrimonial (1822-1930). Ao todo são quatrocentos e trinta anos de culto do privado sobre o público. Portanto, a estruturação do Estado e da Administração Pública aos moldes burocrático e gerencial e sua relação com o sistema político é fato muito recente que segue em implementação.

Ainda que só se possa falar de Administração Pública aos moldes ocidentais com a independência do país, faz-se impossível compreender sua gênese sem o processo histórico que interferiu e interfere diretamente na sua estrutura. A organização administrativa na colônia é marcada por dois grandes momentos: o primeiro, centralizador, liderado pela metrópole e tendo como aliados na colônia o governador-geral, o Conselho Ultramarino e a Igreja Católica; o segundo, mais descentralizado, valorizando as relações de dominações locais, proprietários de terras.

Em síntese, tais momentos são marcados pelo excesso de procedimentos, pela a ideia de que a existência do Estado precede à sociedade e pela a exaltação do privado sobre o público. Só no século XVIII com as reformas pombalinas e a vinda da família real para o Brasil que se passa a construir, em parceria com a Universidade de Coimbra em Portugal, um corpo técnico e político, conhecido como burocracia pombalina que interferirá na independência do país e na construção administrativa do então Brasil.

A administração patrimonial (1821-1930) do Império e da Primeira República fez-se em meio a um Estado Patriarcal-Dependente, tendo como regime político a oligarquia e as classes dirigentes: o latifúndio e a burocracia patrimonial. A elite política e burocrática na administração patrimonial está de alguma forma ligada por vínculos de parentesco, pela terra e por interesses econômicos. O princípio basilar que norteou o Estado é a sobreposição do privado ao público, do clientelismo e da troca de favores entre homens brancos, comerciantes, liberais e proprietários de terra.

O descontentamento da classe média urbana (profissionais liberais, comerciantes, servidores públicos e militares) frente à intransigência da oligarquia cafeeira e sua forma de cooptar o voto aberto da população rural fez surgir a administração burocrática (1930 - 1985). Em meio ao Estado Nacional-Desenvolvimentista, de regime político autoritário, a burocracia pública galga espaço à classe dirigente junto à burguesia industrial e parte da oligarquia. Em especial, na era Vargas, tem-se

Revista do Direito [ISSN 1982-9957]. Santa Cruz do Sul, n. 63, p. 163-185, jan. 2021. https://online.unisc.br/seer/index.php/direito/index 
o aumento do papel do Estado, a profissionalização da burocracia pública aos moldes weberiano e a ampliação das políticas públicas.

Após vinte e um anos de resistência à Ditadura Militar (1964 -1985) o Brasil adentra ao regime democrático. Sua classe dirigente deixa de ser a burocracia pública e a burguesia industrial nacional passando a ser os agentes financeiros e rentistas, pois o Estado se aproxima das ditas potências econômicas mundiais, tornando-se liberal-dependente. A crise fiscal e administrativa que assolou o Brasil fez com que o país na década de 90 adentrasse à administração gerencial em implementação até os dias atuais.

Latifundiários, burocratas patrimoniais, empresários, burocratas públicos, agentes financeiros e rentistas são as classes dirigentes que diretamente interferiram e, muitos de seus herdeiros seguem interferindo, no Estado, no sistema político e na burocracia brasileira. Compreender teoricamente a formação da Administração Pública burocrática e gerencial no Brasil, bem como o desafio de suas relações com o sistema político configuram-se os objetivos do artigo.

Assim, após uma análise da estrutura da Administração Pública burocrática e gerencial travase um debate a respeito dos desafios que precisam ser superados frente a tensionada relação que permeia o sistema político brasileiro e a burocracia, em especial no presidencialismo de coalizão. Para tal, preciso fazer três considerações importantes ao leitor.

Primeira consideração: apesar da relevância do tema, as pesquisas a respeito da burocracia no Brasil são exíguas e quase nunca buscam enfrentar o debate teórico frente ao sistema político. A literatura até apresenta estudos de caso que vinculam a burocracia à administração indireta, à diplomacia ou ao "sucesso" do presidencialismo de coalizão, medido pelo alto índice de aprovação de seus projetos de leis e medidas provisórias em troca de cargos do alto escalão federal. Entretanto, há uma escassez teórica na busca de "[...] entender suas "entranhas" ou sua relação com o sistema político" (BRESSER-PEREIRA, 2010, p. 18). Assim, ao mesmo tempo em que a pesquisa ganha relevância, torna-se desafiadora ao pesquisador.

Segunda consideração: ainda que com frequência se utilize burocracia pública como sinônimo de Estado, a pesquisa que ora será lida não parte desse pressuposto. Seguindo a orientação de Bresser-Pereira compreende-se a burocracia como uma classe profissional que exerce a administração do aparelho do Estado, tendo protagonismo nas escolhas e na efetivação das políticas públicas. É exatamente neste ponto que se estabelece a confusão, pois ao mesmo tempo em que é uma classe profissional, ela integra e interfere diretamente no aparelho do Estado. Entretanto, preciso lembrar que o Estado não se resume a um simples aparelho, organização ou classe profissional.

Terceira consideração: por burocracia entende-se a classe que ocupa cargos de alto escalão ou de direção da administração direta e indireta do Poder Executivo, podendo ser servidores públicos do quadro ou de fora que exerçam atividade na Administração Pública. Enquanto a utilização do termo burocracia refere-se aos atores políticos; aparato burocrático significa agência ou órgão do Estado. Conforme Bresser-Pereira, inclui-se entre os burocratas os políticos profissionais, pois ao longo do tempo foram diluindo o distanciamento técnico que os separavam, portanto para se referir a eles usa-se o termo burocracia política. 


\section{PROCESSO HISTÓRICO DE FORMAÇÃO DA BUROCRACIA PÚBLICA}

É recorrente a utilização do termo burocracia como excesso de exigência que dificulta ou posterga a execução de uma determinada atividade seja na esfera pública ou privada. Recorrentemente a burocracia é vista como um mecanismo que inibe os negócios e atrapalha o cotidiano. Sua compreensão é tão negativa que se apresenta como um dos poucos consensos entre as diferentes correntes político-ideológicas. A direita critica a burocracia por comprometer o livre mercado; o centro problematiza a burocracia por demandar maior transparência e accountability; já a esquerda tenta um esgarçamento da burocracia na busca de construir mais espaço para participação popular e autogestão democrática (BEETHAM, 1996). Embora as críticas à burocracia seja um senso comum no debate político institucional e social sua utilização e relacionamento com o sistema político segue sendo a base dos Estados, em especial dos democráticos de direito. Compreender o processo histórico e teórico de sua estruturação é imperativo para qualquer pesquisador que se proponha a trabalhar o tema, mesmo porque a utilização da burocracia é uma técnica recente que possui em torno de setenta anos na Administração Pública brasileira.

Para Bresser-Pereira a classe empresarial e a alta burocracia pública nas sociedades modernas alcançaram espaços de grupos sociais estratégicos politicamente. No desenvolvimento capitalista, as diversas classes sociais foram sofrendo transformações: a aristocracia para a proprietária rural no século XIX, a burguesa transitando da classe média à alta, parcela da classe trabalhadora adentrando à média, e a burocracia, até então, uma ínfima organização do Estado, alcançando espaço de uma grande classe ${ }^{3}$ profissional ou tecnoburocrata tanto na esfera pública quanto privada. Assim, a alta burguesia (empresários e rentistas), os burocratas (burocracia profissional) e os políticos (burocracia política) constroem seus protagonismos na Administração Pública do Estado (BRESSER-PEREIRA, 2007). "Apesar de contraditórias, as duas lógicas, a de Estado burocrático e a de Estado empresarial, se articulam se complementam, comprovando os efeitos da heterogeneidade social e da fragmentação dos interesses de classes na estrutura do Estado" (LOUREIRO, 2010, p. 84).

A Era das Revoluções é a era das invenções ocidentais. É na Revolução Francesa que a burocracia moderna ganha força, pois a luta burguesa pela limitação do poder do Estado faz surgir uma monarquia constitucional que, inclusive, estrutura o corpo burocrático não mais como propriedade do rei, mas como burocrata público. Para Eric Hobsbawm, o burguês liberal clássico de 1789 não se enquadra como um democrata, mas um devoto do constitucionalismo, do Estado secular com liberdades civis e garantias para a empresa privada e um governo de contribuintes e

\footnotetext{
${ }^{3}$ Marx diverge de Hegel frente à burocracia, pois para aquele a burocracia não é em si mesmo uma classe social, mas uma camada social que se volta para os interesses da classe burguesa e tem como objetivo garantir o status quo por meio da ordem vigente. Indo além, sustenta que a burocracia da esfera pública possui interesses específicos que é o domínio privado pela classe burguesa. Para Marx “A 'burocracia' é o 'formalismo de Estado' da sociedade civil. É a 'consciência do Estado', a 'vontade do Estado', 'o poder do Estado' enquanto corporação, isto é, como sociedade particular, fechada no Estado [...] A burocracia é portanto obrigada a proteger a generalidade imaginária do interesse particular a fim de proteger a particularidade imaginária do interesse geral". (Marx, 1983, p. 64).
}

Revista do Direito [ISSN 1982-9957]. Santa Cruz do Sul, n. 63, p. 163-185, jan. 2021. https://online.unisc.br/seer/index.php/direito/index 
proprietários (HOBSBAWM, 2017). A estrutura burocrática, ainda que de forma tímida, passa a ser perseguida pelo Estado como "direito de todos" no século XVIII. Não por menos, adentra à Declaração dos Direitos do Homem e do Cidadão no Art $6^{\circ}$ ao sustentar que "todos os cidadãos são iguais a seus olhos, são igualmente admissíveis a todas as dignidades, lugares e empregos públicos, segundo a sua capacidade, e sem outra distinção que não seja a das suas virtudes e dos seus talentos" (FRANÇA, 2019).

O capitalismo atinge seus objetivos potencialmente na Revolução Industrial. O regime democrático dominante no fim do século XX e a conquista das classes populares por direitos civis e políticos levaram ao liberalismo e, mais adiante, ao Estado de Bem-Estar Social. A administração burocrática, engenhada no liberalismo, apresentou-se como única estrutura capaz de efetivar as muitas promessas do Estado de Bem-Estar Social e garantir a plenitude do status quo da classe dirigente.

O patrimonialismo ${ }^{4}$ baseado nos modelos dos Estados Absolutistas até então vigente se fez incapaz de garantir os novos direitos civis, políticos e individuais pleiteados pela corrente liberal, bem como de adequar-se à administração racional-legal que ganha lastro com as teorias de Weber. $\mathrm{O}$ patrimonialismo em total declínio se apresentou como a "[...] incapacidade ou a relutância de o príncipe distinguir entre o patrimonialismo público e seus bens privados" (BRESSER-PEREIRA, 2006, p. 26).

A burocracia ganha maiores contornos científicos a partir da teoria do liberal Max Weber que atribui ao termo a especialização técnica do corpo que compõe a estrutura organizacional. A burocracia weberiana está intimamente ligada à autoridade legal. Assim, o corpo de funcionários que constituídos dentro de uma configuração peculiar e submetidos às normas de conduta, também peculiares e determinadas, praticam autoridade legal. O quadro administrativo burocrático é definido por Weber como a mais pura dominação legal. São pessoas livres, nomeadas dentro de uma hierarquia e um contrato, exercendo competências funcionais fixas, atendendo uma qualificação para um certo cargo (profissão), obtendo remuneração, carreira e um sistema rigoroso e homogêneo de disciplina e controle do serviço (WEBER, 1999).

Para Weber, a administração e a política não estão imbricadas. Enquanto a administração está aos burocratas a política está aos parlamentares. Assim, no Estado Moderno a burocracia detém o poder que não é exercida "por meio de discursos parlamentares nem por falas de monarcas, mas sim, mediante a condução da administração, na rotina do dia-a-dia" (Weber, 1997). Ainda que seja um dos principais teóricos do tema, a burocracia weberiana passa a sofrer críticas, em especial, referente ao ensimesmado, as disfunções, os insulamentos burocráticos, bem como seu distanciamento do Estado Democrático.

\footnotetext{
4“O patrimonialismo, organização política básica, fecha-se sobre si próprio com o estamento, de caráter marcadamente burocrático. Burocracia não no sentido moderno, com o aparelhamento racional, mas da apropriação do cargo - o cargo carregado de poder próprio, articulado com o príncipe, sem anulação da esfera própria de competência. O Estado ainda não é uma pirâmide autoritária, mas um feixe de cargos, reunidos por coordenação, com respeito à aristocracia do subordinado. A comercialização da economia, proporcionando ingressos em dinheiro e assegurando o pagamento periódico das despesas, permitiu a abertura do recrutamento, sem que ao funcionário incumbissem os gastos da burocracia, financiando os seus dependentes". (FAORO, p. 84).
} 
Entretanto, é preciso apresentar a defesa ao autor, uma vez que chega a destacar o risco de a burocracia utilizar da autonomia funcional para garantir interesses pessoais, bem como o perigo da improdutividade do agente burocrático. Para Weber a burocracia pública, para além de racionalizar a atividade estatal, precisa proporcionar o caráter público do Estado, não restar concentrada, respeitar o princípio da impessoalidade e o desempenho deve ser o melhor possível.

Caso contrário, a racionalização burocrática na sociedade de massa traria empecilhos às liberdades individuais tão arduamente defendidas por Weber. Ao longo de sua obra, chega a destacar que "o fim precípuo de nossa época, caracterizada pela racionalização, pela intelectualização e, principalmente, pelo 'desencantamento do mundo' levou os homens a banir da vida pública os valores supremos e mais sublimes" (WEBER, 2002).

O Estado Moderno é um grande divisor de águas para a burocracia. Num primeiro momento, a burocracia tradicional estrutura-se embasada em relações pessoais de mando e subordinação do detentor do poder. Num segundo momento, com a estruturação da Administração Pública burocrática busca-se se despersonalização do detentor maior do poder, passando a ter uma estrutura objetiva, universal e impessoal previamente definida. Assim, a burocracia europeia engenha os moldes de racionalidade e legalidade da Administração Pública que percorrerá parte da América, em destaque o Brasil.

\section{ADMINISTRAÇÃO PÚBLICA BRASILEIRA: DA PATRIMONIALISTA À BUROCRÁTICA}

Os trezentos e vinte dois anos de colonização brasileira erigiram a estrutura estatal aos moldes do desejo do colonizador. Sérgio Buarque de Holanda define a formação portuguesa como uma burguesia mercantil que alça espaço dentro da administração encastelando a burocracia patrimonialista . É nesse cenário que "a sociedade civil e política são consideradas uma espécie de prolongamento ou ampliação da comunidade doméstica" (FREYRE, 1992, p. 155). Raimundo Faoro aduz que "o patrimonialismo pessoal se converte em patrimonialismo estatal, que adota o mercantilismo como a técnica de operação da economia" (FAORO, 2001, p. 823)

A burocracia no período patrimonialista diverge da sustentada por Weber, uma vez que aquela é representada pela "apropriação do cargo - o cargo carregado de poder próprio, articulado com o príncipe" (FAORO, 2001, p. 84). Como sustentam Gilberto Freyre (1992) e Sérgio Buarque de Holanda (2009) o Estado oligárquico brasileiro até 1930 era fortemente dominado por uma oligarquia proprietária de terra e que, ao mesmo tempo, exercia o comércio.

O Brasil viveu três momentos de reformas administrativas durante o século $X X$, do afastamento do patrimonialismo à busca pela modernização da burocracia. Coincidentemente, de três em três décadas há uma tentativa de um novo pacto administrativo: 1930, 1960 e 1990. Importante ressaltar que as duas primeiras se deram em regime de exceção e a última em democracia de baixa intensidade.

As promessas da modernidade ocidental, em destaque a Administração Pública burocrática aos moldes weberiana, chegam com atraso no Brasil frente a Europa. Só por volta de 1930 e 1960 com a aceleração industrial. Mesmo assim, o Brasil caminha ao encontro das sociedades capitalistas 
do início do século XX. A busca pelo desenvolvimento industrial e econômico liderada pelo Estado passam a demandar uma maior estrutura burocrática. Como afirma Gorender, o Estado foi fiador do desenvolvimento industrial; a iniciativa privada era incipiente e incapaz economicamente 5 . "O foco é o papel central assumido pelo Estado a partir de 1930 na construção do projeto nacionaldesenvolvimentista, num contexto marcado pela ausência de hegemonia do empresariado e da fragmentação social" (LOUREIRO, 2010, p. 84).

A administração burocrática apresentou-se como uma demanda do capitalismo em uma suposta busca de vencer o patrimonialismo, o clientelismo, o coronelismo, o nepotismo e o empreguismo. Para a separação formal entre o Estado e o mercado, desenvolve-se um tipo de administração que busca delimitar não apenas o contorno entre o público e o privado, mas, também, o político partidário do administrador público burocrático. É com essa difícil missão frente ao passado fortemente patrimonialista que surge a administração burocrática moderna, racional e legal na Administração Pública Brasileira.

Emerson Gabardo faz um importante alerta ao que se refere às raízes da burocracia brasileira. Ainda que seja pensada dentro de um Estado formalmente público, o espólio do patrimonialismo insiste em adotar práticas que o arremesse à interesses materialmente privados (GABARDO, 2002).

Para Bresser-Pereira o país economicamente situa-se na fase do Capitalismo Global e do ponto de vista social está na fase do Capitalismo dos Profissionais. Logo, o capitalismo não engloba apenas o sistema econômico e social, abarca, também, os profissionais ou técnicos repletos de poder e privilégio. "São os profissionais públicos a alta burocracia pública que dirige os Estados democráticos modernos; dirigem-nos em nome do resto da sociedade mas, evidentemente, também em nome de seus interesses e conviç̧ões" (BRESSER-PEREIRA, 2007, p. 4).

$\mathrm{Na}$ América Latina, as décadas de 1930 a 1980 são marcadas por acordos com as elites internacionais que colocaram as nações em situações de subordinação. Por cinquenta anos, os países posicionaram-se como sociedades nacionais-dependentes das elites econômicas internacionais (BRESSER-PEREIRA, 1999, p. 4). O resultado foi a grande crise da dívida externa e a alta inflação que assolou várias nações. O pano de fundo para o auge da hegemonia ideológica americana que conquistou boa parte da América se deu graças ao que Marx e Engels chamaram de "fantasma do comunismo" e "caçada santa a esse fantasma" (MARX, 2012).

A compreensão apresentada por Bresser-Pereira de tal momento é de que os Estados nacionais, ainda que em agudas crises, não perderam relevância, pelo contrário, o momento era de formulação de políticas públicas peculiares às suas demandas. Chegando a sustentar um acordo nacional amplo baseado na associação entre os grandes empresários e a alta burocracia pública. Indo além, aduz que o liberalismo econômico radical não representa a lógica da eficiência do capitalismo dos profissionais que, ainda que depositem esperanças no mercado como coordenador automático da atividade econômica, sabe das suas limitações, portanto, tem no Estado aquele capaz

\footnotetext{
54Durante os anos 30, os porta-vozes dos industriais enfatizaram dois pontos: 10 necessidade de financiamento do Estado para a industrialização; 2ำ criação pelo próprio Estado de núcleos da moderna indústria de base (ferro e aço, produtos químicos, petróleo), cuja construção se achava fora do alcance do capital privado (GORENDER, 2004, p. 71).
} 
de regulá-lo e corrigi-lo para, assim, alcançar maiores taxas econômicas (BRESSER-PEREIRA, 1999).

É bem verdade que a ideologia neoliberal e globalista é reflexo da crise vivida nos Estados Unidos na década de 1970 desencadeada por inúmeros fatores, destacando: lutas trabalhistas por melhores salários; competitividade gerada pelos novos países que passaram a exportar suas próprios manufaturados usando mãos de obras baratas; preços das commodities; mas, também, está vinculado ao aumento do poder da alta burocracia pública nos países ricos em função do crescimento do aparelho do Estado Democrático e Social de Direito.

No Brasil e em boa parte da América Latina a onda neoliberal e globalista acarretou mudanças estruturais, em especial à ruptura da aliança nacional entre o empresariado e a alta burocracia pública. O neoliberalismo brasileiro dá início no mesmo momento em que o país está se redemocratizando. Assim, no plano político tem-se o afastamento dos grandes empresários frente à alta burocracia brasileira, e, no plano econômico estabelece-se um programa de interesse nacional.

A administração burocrática no Brasil ganha estrutura na gestão do presidente Getúlio Vargas (1930-1945; 1951-1954), em especial com a criação do Departamento de Administração do Serviço Público (DASP), por meio do Decreto-Lei no 579, de 30/07/1938 (BRASIL, 1938). O órgão se engenha, a partir da teoria weberiana, na busca de dar corpo à burocracia por meio da meritocracia profissional. Foi o momento de nascedouro "[...] de uma burocracia meritocrática, profissional e universalista, que, ao atuar como o motor da expansão desenvolvimentista do Estado, tornou-se então a primeira estrutura burocrática weberiana destinada a produzir políticas públicas em larga escala" (ABRUCIO, 2010, p. 27).

A atuação da DASP, apesar de inovadora possuía limites. Sua rigidez burocrática e incapacidade de vencer o clientelismo no loteamento dos cargos, após trinta e um anos entra em colapso e sofre alterações pelo Decreto-Lei no 200/67 (BRASIL, 1967.

Tal momento pode ser compreendido como um ensaio à administração gerencial no país, dando ênfase à descentralização e à desburocratização da administração. Entretanto, na via inversa, os grupos historicamente detentores do poder como a alta burocracia estatal, os civis e militares e a classe empresarial conseguiram manter-se unidas e utilizando de práticas patrimonialistas. Para Bresser-Pereira "o DASP foi o agente principal da Reforma Burocrática" (BRESSER-PEREIRA, 2019).

É fácil notar que o discurso de legitimação dos militares estruturou-se pautado em três argumentos: patriotismo, anticomunismo e a ideologia antipolítica e tecnoburocrática. Motivo pelo qual a Administração Pública passa a ser objeto de inúmeras legislações, inclusive vigentes até os dias de hoje (LOUREIRO, 2010).

Entretanto, a herança sempre presente do patrimonialismo, em especial num período de Ditadura Militar, fez com que o Decreto-Lei ํㅜ 200/67 permitisse a contratação sem concurso público, bem como o não desenvolvimento das carreiras de altos administradores. Numa tentativa de reverter a situação precária em que se encontrava a Administração Pública criou-se a Secretária de Modernização, na década de 70 , sem apresentar grandes resultados. A crise fiscal, gerencial e humanitária levou a Ditadura Militar ao colapso. 


\section{DA REDEMOCRATIZAÇÃO À ADMINISTRAÇÃO PÚBLICA GERENCIAL}

A situação econômica, política e social do país, após vinte e um anos de governo de exceção, empurrou o Brasil a uma grande crise institucional, capaz de transcender seu tempo. Para BresserPereira "[...] a transição democrática teve também um preço: o retrocesso burocrático de 1988" (BRESSER-PEREIRA, 2007, p. 44).

Entre os pontos mais criticados do texto constitucional frente à burocracia estão o excesso de poder aos governantes (barões da federação), o exagero de descentralização para os estados e municípios e o retorno da centralização da administração indireta para a direta (ABRUCIO, 1994).

Para Bresser-Pereira, o constituinte originário de 1988 usou como referência, para seu texto, a Reforma Burocrática de 1936. O objetivo era combater a desconcentração e a flexibilização defendida pelo Decreto-Lei no 200, tidas, equivocadamente, como principal motivo da crise em curso. É nesse contexto que a Administração Pública retorna ao status de hierárquica e rígida, ao ponto que desaparece a distinção entre administração direta e indireta. Ao mesmo tempo em que o retrocesso burocrático representou uma reação ao clientelismo que imperou no Brasil, foi, também, uma manutenção de privilégios corporativistas e patrimonialistas bem distante do ethos burocrático (BRESSER-PEREIRA, 2007, p. 46).

O Governo de Fernando Collor de Mello (1990-1992) apresentou uma reforma administrativa. Entretanto, a burocracia sofreu um radicalismo, em especial com a desestatização, privatização, a demissão em série de servidores públicos para diminuir a máquina pública e, por fim, a abertura do mercado ao comércio internacional. Para Castor a tentativa restou infrutífera não só pela incongruência de tais medidas como também pela derrocada da burocracia gerencial até então conquistada (CASTOR, 2004). Um das poucas medidas que se destacam é a tentativa de levar a gestão do setor privado para o público intitulada como estratégia de qualidade total.

A crise fiscal do Estado e a crise da Administração Pública é intensificada com o pacto liberaldependente que Collor insere o Brasil. Rentistas, setor financeiro, multinacionais e a os países ditos desenvolvidos ganham espaço privilegiado em sua administração e, portanto, gesta o total distanciamento com o empresariado industrial e a burocracia que, por mais de 56 anos, haviam sido as duas classes dirigentes de maior relevância na política nacional.

No entender de Bresser-Pereira, a saída para tal crise não era trocar o Estado pelo o mercado como se defendia a ideologia liberal, mas apresentar uma reforma e reconstrução do Estado para que o mesmo se apresentasse como um agente efetivo e eficiente na regulação do mercado e na estruturação das empresas para a competitividade internacional (BRESSER-PEREIRA, 2007, p. 50). É nesse cenário desfavorável à burocracia pública que o governo Fernando Henrique Cardoso (1995 - 2003) propôs a terceira reforma administrativa que é a reforma gerencial. Diferente das duas outras reformas, esta seria executada dentro de um Estado Democrático.

As duas frentes da reforma gerencial se deu com a proposta de Emenda Constitucional no capítulo da Administração Pública e no Plano Diretor da Reforma do Aparelho do Estado - PDRAE. Bresser-Pereira como Ministro da Administração Federal e Reforma do Estado - MARE, embasado nas práticas implantadas na Inglaterra e Nova Zelândia, foi o responsável por tentar um afastamento 
da burocracia aos moldes de Max Weber, tida como ineficiente, lenta, autorreferencial e distante das demandas sociais, bem como de uma aproximação junto à administração gerencial.

Nos primeiros seis meses de governo de Fernando Henrique foi lançada a estrutura da administração gerencial por meio do Plano Diretor da Reforma do Aparelho do Estado. A reforma gerencial se apresenta por meio da ideia de que o Estado precisava ter definido de forma clara seu papel frente à sociedade. "Procura responder quais são as atividades que o Estado deve realizar diretamente, quais deve apenas financiar ou promover, e quais as que não the competem" (BRESSER PEREIRA, 1998, p. 95). SEE PEP Para o então ministro, se fazia imprescindível estabelecer uma nítida separação não apenas entre as atividades do Estado e do mercado, mas, também, entre o sujeito político e o administrador público. O PDRAE deixa claro que seu objetivo é uma reforma do aparelho do estado que transite da burocracia ao gerencialismo.

Utilizando dos princípios da gestão pela qualidade trouxe a iniciativa privada para produção de serviços competitivos ou aqueles que não fossem de exclusividade do poder público. A famosa parceria público-privada no investimento e controle de determinadas atividades ganha estada na Administração Pública. É uma forma de esvaziar o Estado e transferir à esfera privada todas as modalidades de atividades cabíveis ao mercado. A reforma se funda na busca incessante pela diminuição dos custos, melhoria e eficiência na prestação do serviço público e no cidadão-cliente aos moldes da iniciativa privada. Corrobora Emerson Gabardo que as promessas da reforma gerencial "[...] propugnava por uma Administração Pública voltada para o "cidadão-cliente" ou "cidadãousuário", com vistas à melhoria da governança do Estado. Pretendia-se, portanto, mais do que uma evolução para a democracia, uma verdadeira reforma na própria democracia" (GABARDO, 2009, p. 98). Outra promessa é a descentralização administrativa e política para agentes e órgãos públicos.

Dando sustentação ao PDRAE, a Emenda Constitucional no 19, de 04 de junho de 1998, é o marco jurídico-constitucional da reforma gerencial. Para além de incluir a eficiência como princípio nuclear da Administração Pública (Art. 37), trouxe mudanças no regime de trabalho e remuneração dos servidores públicos, bem como flexibilização na esfera de prestação de serviços públicos. Indo ao encontro da reforma gerencial, aprovou-se a Emenda Constitucional o 20 que fixou idade à aposentadoria.

Após aprovado o arcabouço da reforma gerencial, inclusive, constitucionalmente, era preciso que o governo investisse forças para a fase de implementação. Ocorre que, o próprio Fernando Henrique, não conseguiu arcar politicamente com a execução da reforma administrativa, dando maior atenção à estabilização econômica. Inclusive, em seu segundo mandato, extinguiu o MARE e abandonou a agenda da gestão pública (ABRÚCIO, 2011). Segundo Flávio Rezende apesar da reforma não ter conseguido êxito ao que tange as políticas de mudanças institucionais, a mesma foi imprescindível para o ajuste fiscal (REZENDE, 2002).

\section{A HERANÇA DA REFORMA GERENCIAL NOS GOVERNOS LULA E DILMA AO MICHEL TEMER}


Apesar de Luiz Inácio Lula da Silva (2003 - 2010) chegar à presidência com forte crítica à reforma gerencial adotada pelo antecessor Fernando Henrique Cardoso, taxada de neoliberal, ao assumir não a descartou. Bresser-Pereira, o próprio idealizador de tal reforma, chega a afirmar que, até 2003, a reforma foi relativamente paralisada, mas, posteriormente, o governo Lula passou a adotar inúmeros princípios da mesma aos seus moldes (BRESSER-PEREIRA. 2007). Nesse sentido, ainda que tenha sido contrário à privatização, fortemente defendida pela reforma gerencial, aprovou a Lei das Parcerias Público-Privada (PPPs) que ampliou a concessão de estradas e firmou parcerias com a iniciativa privada na esfera do Plano de Aceleração do Crescimento (PAC). "Com isso, fica claro que a Reforma Gerencial de 1995 continua viva mesmo no nível federal” (BRESSER-PEREIRA, 2007).

Diferente de Fernando Henrique, Lula não adotou uma política centralizadora na gestão pública. Todavia, frente às novas e muitas políticas públicas desenvolvidas por seu governo, ampliou a intervenção estatal, bem como passou a demandar uma maior qualificação na prestação. Portanto, as políticas públicas assumiram o carro chefe do seu governo e, consequentemente, da agenda administrativa. Apesar de ter sido o Partido dos Trabalhadores (PT) aquele que mais se opôs às propostas do Plano Diretor de Fernando Henrique, chegando ao poder, "[...] mais se utilizou de uma parte de suas propostas, em particular no que se refere ao uso de metodologias e instrumentos qualitativos e quantitativos de monitoramento de políticas públicas" (PESSOA, 2015).

. Nesse mesmo sentido, sustenta Abrucio "é mais correto analisar o período Lula como um caminho marcado por contradições e pela adoção fragmentada e difusa da gestão por resultados, em vez de classificá-lo predominantemente como uma rejeição integral das ideias bresserianas" (ABRÚCIO, p. 123).

Políticas públicas como o Bolsa Família, Programa Universidade para Todos (ProUni), Índice de Desenvolvimento da Educação Básica (IDEB), Programa de Aceleração do Crescimento (PAC), Minha Casa Minha Vida entre outras, para além de serem prestações públicas inovadoras, nasceram acompanhadas de instrumentos burocráticos de monitoramento de sua qualidade. Ao mesmo tempo repletas de desafios, pois há um tensionamento entre a burocracia e o sistema político no comando e execução de tais políticas.

Outra importante medida foi a criação do Conselho de Desenvolvimento Econômico e Social (CDES) responsável por garantir com que o Presidente não se feche na burocracia, acarretando o insulamento. Indo além, implementou e fortaleceu a Controladoria Geral da União (CGU) como órgão interno do Governo Federal responsável pela defesa do patrimônio público, a transparência da gestão e supervisão técnica. Por meio da Lei Complementar № 131/2009 deu transparência as informações sobre a execução orçamentária e financeira dos entes federados disponibilizando, em tempo real, por meio do Portal Transferência. Tais estruturas são formas cristalinas de controle da burocracia púbica indo ao encontro da Reforma Gerencial.

Os seis anos de governo Dilma Rousseff (2011-2016) seguiram os traços gerais do seu antecessor na busca da inclusão social por meio de políticas públicas. Para além de dar continuidade, criou novas políticas públicas como Mais Médicos, Ciência Sem Fronteira, Institutos Técnicos Federais, Luz para Todos, entre outros. Assim como Lula, Dilma não apresentou uma agenda 
administrativa específica, segue em parte as diretrizes da reforma gerencial de Fernando Henrique. $\mathrm{Na}$ esfera burocrática, para além de criar novas carreiras públicas e políticas públicas, o governo adota a técnica bressiana de enxugamento da máquina pública, fez inúmeras concessões de aeroportos, terminais, ferrovias e rodovias.

Michel Temer (2016-2018) e seu mandato presidencial questionável ${ }^{6}$ por meio de um "tropeço" na democracia (LINDNER, 2017), citando palavras do Ministro Lewandowski do STF, não precisou "[...] de nenhuma reforma organizacional do aparelho do Estado. Basta usar a estrutura posta em cena pelos governos anteriores" (MISOCZKY; DAMBORIARENA, 2017, p. 192). Por meio da Medida Provisória № 726/2016 (BRASIL, 2016), Temer abre sua reforma administrativa e cria uma organização presidencial e ministerial que caibam seus aliados, em especial integrantes dos partidos que o ajudaram na tensionada escalada ao poder.

Sobre o manto de diminuir a Administração Pública, Temer transforma de 32 para 26 ministérios e por meio do Decreto № 9.262 (BRASIL, 2016) extingue cargos efetivos vagos e aqueles que vierem a vagar dos quadros de pessoal da Administração Pública Federal e veda abertura de novos concursos para os cargos especificados. Por meio da medida recorrente, desde a redemocratização, utilizada por todos os presidentes, exceto Itamar Franco, Temer criou duas medidas. Primeiro, via Decreto de 7 de março de 2017 (BRASIL, 2016) instituiu o Conselho Nacional para a Desburocratização - Brasil eficiente. Segundo, sancionou a Lei oㅜ 13.726/2018 (BRASIL, 2018) prometendo racionalizar atos e procedimentos dos Poderes da União, dos Estados, do Distrito Federal e dos Municípios e instituiu o Selo de Desburocratização e Simplificação. No mais, segue a reforma gerencial aos moldes de seu governo tampão.

O saldo das reformas administrativas no Brasil não é positivo. Elas dificilmente conseguem atingir seus objetivos, pois são envoltas por problemas de performance, outras reformas são formuladas e postas para tentar resolver antigos problemas. Assim, "o caso brasileiro historicamente representa um modelo de falhas sequencial, i.e., as reformas dificilmente conseguiram alterar a performance do aparato burocrático" (REZENDE, 2002, p. 62).

Assim, há uma baixa performance nas reformas administrativas que, por consequência, gestam um colapso na estrutura administrativa.

\section{O DESAFIO dA BUROCRACIA PÚblicA FRENTE AO SISTEMA POLítico NO PRESIDENCIALISMO DE COALIZÃO BRASILEIRO}

Tentando problematizar a relação do sistema político com a burocracia e as bases institucionais do presidencialismo de coalizão, Fernando Limongi e Argelina Figueiredo, no ano de promulgação do texto constitucional, lançaram alguns questionamentos que permanecem atuais e valem ser revisitados: "[...] por que o Executivo se disporia a entregar uma nomeação por um preço tão baixo? Um só voto? Por que não ocorreria ao Executivo condicionar a nomeação à obtenção de

\footnotetext{
${ }^{6} \mathrm{~A}$ respeito do assunto ver: A resistência ao golpe de 2016. (PRONER; CITTADINO; TENEBAL; RAMOS FILHO, 2016).
} 
dois votos? E por que não a três? E por que não a uma determinada agenda?" (LIMONGl; FIGUEIREDO, 1998, p. 96).

Após trinta anos de tais questionamentos, algumas respostas foram alcançadas pela doutrina, outras permanecem intocáveis e precisam ser encaradas. Entre as respostas alcançadas, a primeira é que, por mais dificultosa que seja a relação entre o presidencialismo de coalizão, a burocracia e o sistema político o país é 'governável' (FREITAS, 2013, p. 21).

. Correntes majoritárias já refutam as teses defendidas por Abranches e Mainwaring de que o presidencialismo de coalizão é problemático, explosivo e ingovernável. Nesse sentido, aduz Limongi que "O Brasil não é tão diferente dos países parlamentaristas" (LIMONGI, 2006, p. 23). O medo de que a burocracia, o federalismo, o pluripartidarismo e o presidencialismo gestavam frente a governabilidade em 1988 não mais se apresentam com tamanha intensidade. Inclusive, a resposta do porquê o Executivo se dispõe a entregar nomeações à partidos políticos, segundo boa parte dos pesquisadores, reside na capacidade do presidente em ser autor de expressiva quantia de leis (taxa dominância), bem como de deter altos índices em suas aprovações (FIGUEIREDO; LIMONGI, 1999) - em especial, medidas provisórias e projetos de lei - (taxa de sucesso).

De acordo com Andrea Freitas "as explicações para o sucesso e dominância tem como base os poderes do presidente - os poderes de agenda, o controle discricionário sobre cargos e sobre o orçamento" (FREITAS, p. 21, 2013). Aqui encontra-se uma das respostas não alcançadas pelos questionamentos supramencionados e que merece ser enfrentada. Se pelo lado da governabilidade os dados são positivos o Poder Executivo detém o poder de agenda e controle sobre cargos e orçamento como moeda de troca. Para o sistema político, pelo viés burocrático, tal prática é positiva? A resposta que se quer encontrar, para além do alto índice de aprovação obtida pela coalizão Executivo-Legislativo, é qual é o preço da politização da burocracia no presidencialismo de coalizão brasileiro.

De antemão, importante destacar que não se está a defender a tese de Woodrow Wilson da separação entre política e burocracia, em que políticos decidem e os burocratas, de forma isolada, executam e administram. Distante desta harmonia, a relação entre burocracia e política como sustenta Weber se perfaz por meio de convício necessário e tensionamentos constantes. Portanto, "[...] afirmar a relevância dos burocratas nas decisões governamentais não significa ignorar sua dependência institucional em relação à autoridade política, nem tampouco negar que a responsabilidade última pelas decisões é dos políticos, como Weber já havia apontado" (LOUREIRO; OLIVIERI; MARTES, 2010, p. 75).

Vive-se de forma híbrida a burocratização da política e a politização da burocracia. Aos poucos os burocratas foram alçando autonomia na atribuição de suas atividades, mesmo porque o político frente ao agigantamento do Estado e suas muitas promessas de Bem-Estar Social passa a ter dificuldade técnica na execução das mesmas. "Como há uma multiplicidade de burocracias para atender a diversas clientelas, elas ajudam a setorizar as reinvindicações e tornam o Estado capaz de lidar com pressões diferentes e até com demandas diferentes (LOUREIRO; OLIVIERI; MARTES, 2010, p. 75). 
Para Felix Lopes e Sérgio Praça a ascendência da política, em destaque dos partidos políticos, sobre os cargos de nomeação traz consigo marcas tanto do incentivo institucional quanto da formação histórica do país. O patrimonialismo segue sendo a forma secular de maior vigência no país, portanto não é uma prática exterminada. Os autores chamam atenção para dois pontos: o primeiro ponto é que as regras eleitorais como postas acabam estimulando as estratégias localistas e distributivas dos parlamentares, além do personalismo; o segundo ponto é que a estrutura federativa e sua centralização nas políticas e nos investimentos de recursos em nível federal aumentam o papel do controle de espaços de poder como tática para interferir em políticas e decisões na arena política subnacional (LOPEZ; PRAÇA, 2015).

Os cargos e aparatos burocráticos para além de se construírem como uma extensão do Poder Executivo em nível regional, empoderam aqueles que localmente os ocupam. Este exerce o papel de interlocutor do Governo Federal e detém a capacidade de incluir via políticas públicas cidadãos ávidos por direitos básicos que o Estado de Bem-Estar Social pouco cumpriu. Em tempos de política públicas estruturantes como Minha Casa Minha Vida, Luz Para Todos e Bolsa Família controlar tais políticas nacionalmente e regionalmente é uma forma de garantir espaços de poder e projeção aos políticos e seus partidos. Portanto, "É sintomático haver forte cobiça por controlar politicamente a nomeação de cargos federais cuja lotação ocorre nas bases eleitorais dos parlamentares" (LOPEZ; PRAÇA, 2015).

A politização da burocracia é uma das estratégias utilizada pelo presidencialismo de coalizão para que o Chefe do Executivo garanta seus interesses dentro do Congresso Nacional, inclusive de legislar, por meio da construção de uma maioria suprapartidária. Em contrapartida, garante ao Poder Legislativo a participação na gestão, por meio de cargos do alto escalão da Administração Pública Federal. É a reserva burocrática do Poder Executivo que se orienta por políticas, cargos ou votos (MULLER; STROM, 1999).

Como aduz Batista "ministros e partidos por trás desses ministérios influenciam as decisões do Executivo, de forma que controlar um ministério é um instrumento de acesso privilegiado a decisões importantes para o partido, e não simplesmente mais um cargo" (BATISTA, 2013, p. 183).

Assim, membros de partidos e políticos eleitos disputam por espaços dentro da burocracia administrativa na busca de poder intervir no orçamento público e nas políticas públicas que vem se avolumando desde a redemocratização. É uma forma de compor a base presidencial no Congresso Nacional e, assim, garantir governabilidade e êxito legislativo ao presidente (AMORIM NETO, 2006).

Mesmo porque, segundo Sérgio Abranches "[...] no Brasil, sem base de apoio político no Congresso Nacional, um governo não se torna capaz de viabilizar suas iniciativas no processo de implementação da política estatal" (MARTUSCELLI, 2010, p. 61). Indo além, sustenta que a base de apoio do presidencialismo se estrutura por meio de três momentos fundamentais: aliança eleitoral (campanha eleitoral), constituição do governo (nomeações) e coalizão governamental (implantação das políticas). "A formação da coalizão pós-eleitoral implica em definir a fatia de poder de cada partido, conciliando diferentes dimensões no jogo de barganha" (LOPEZ; PRAÇA, 2015, p. 39).

Danilo Martuscelli apresenta dois limites à forma de análise feita ao funcionamento do presidencialismo de coalizão. Primeiro limite: sua crítica está pautada no formalismo como se mede o 
sucesso do presidencialismo de coalizão por meio da politização da burocracia (distribuição de cargos) que, por consequência, garantirá aprovação legislativa (projeto de lei e medidas provisórias) ao Chefe do Executivo. Esta fórmula está totalmente apartada do debate da estrutura econômica e social. "Isto as impede de explicar a relação entre as instituições políticas e os interesses de classe em disputa na cena política, ou mesmo, de compreender a correlação existente entre política e economia" (MARTUSCELLI, 2010, p. 63). Segundo limite: no Estado burguês a híbrida relação construída por meio da coalizão entre o executivo e o legislativo tem feito com que, diuturnamente, se amplie a relativização da tese da separação dos poderes. Lembrando que se está a falar a respeito do agigantamento do Executivo sobre os interesses dos Estados (Senado) e o Povo (Câmara dos Deputados). O agigantamento do executivo sob o legislativo influencia diretamente a natureza do regime político adotado.

o regime político constituído no país no pós-1988 conferiu muito mais capacidade de decisão à burocracia estatal, garantindo, assim, uma legitimidade burocrática em vez de uma legitimidade representativa, pautada nas ações do Parlamento. Com isso, é possível sustentar que se consolidou no país 0 que alguns autores chamaram de "hiperpresidencialismo", que relega ao segundo plano as funções governativa e representativa dos partidos políticos e fortalece a figura do presidente da República junto ao conjunto do eleitorado (MARTUSCELLI, 2010, p. 63).

Assim, a coalizão que fortalece o presidencialismo e, automaticamente, busca vitórias homogeneizantes no debate feito no congresso, na via inversa, enfraquece a participação popular e a pluralidade de ideias dos congressistas. Nesse mesmo sentido, Andrea de Freitas aduz que "no momento em que o presidente divide seu poder com os partidos políticos que compõem sua coalizão, ele firma um acordo que obscurece as distinções entre o Poder Executivo e o Legislativo" (FREITAS, 2013, p. 23).

Para Abrucio falta modernizar a relação dos partidos com a gestão pública. É preciso modernizar o presidencialismo de coalizão assim como foram feitas grandes reformas como o Plano Real, o Bolsa Família, o Portal da Transparência entre outras (ABRÚCIO, 2011).

A cooptação de partidos pela politização da burocracia diminui o Congresso a um grupo de parlamentares que pelejam por um bocado de recursos e cargos leiloados pelo presidente. Tal interpretação diminui o Legislativo e o Executivo a dois atores unitários, focados na política de coalizão, mas distantes da realidade do povo. Ambos teriam um único objetivo final que se resume: a reeleição (FREITAS, 2013, p. 23). Nesse mesmo sentido, Felix Lopez, Maurício Bugarin e Karina Bugarin sustentam que "a fragmentação partidária aumenta a competição por cargos, por haver maior diversidade de lideranças políticas dispostas ao controle de posições de alto escalão na burocracia" (LOPEZ; BUGARIN; BUGARIN, 2015, p. 35).

Esse debate precisa ser enfrentado, pois a proliferação de partidos só tem aumentado no país. Analisando os mandatos já encerrados, desde a redemocratização: em 1988 a Câmara dos Deputados recepcionou 18 partidos com representantes eleitos; em 2002 foram 19; em 2006 foram 21; em 2010 foram 22 e, por último, em 2014 foram 27 partidos. Enquanto em 1988 um único partido, 
como o extinto PFL, possuía 105 deputados, em 2014 o PT, partido melhor votado, obteve 68 deputados. Indo além, em 1998, 10 partidos detinham 492 deputados dos 513, em 2014, 18 partidos passaram a deter 492 deputados. Tais dados mostram por si só o quão dificultoso vem se tornando a articulação do Chefe do Executivo frente à burocracia e o sistema político. ${ }^{7}$

A pulverização de partidos faz com que a coalizão demande mais ministérios e cargos para que se recepcionem os partidos das mais variadas vertentes ideológicas e, assim, preservando ao Presidente seu status de maior propositor de lei e de índices de aprovações elevadíssimos.

Outro ponto crítico ao presidencialismo de coalizão é a cooptação do líder partidário que construirá a disciplina partidária sobre seus membros por meio da politização da burocracia. Ainda que os votos dos representantes do legislativo possuam igual valor, internamente, organizam-se pela proporcionalidade partidária.

O Executivo domina o processo legislativo porque tem poder de agenda e esta agenda é processada e votada por um Poder Legislativo organizado de forma altamente centralizada em torno de regras que distribuem direitos parlamentares de acordo com princípios partidários. No interior deste quadro institucional, o presidente conta com meios para induzir os parlamentares à cooperação. Da mesma forma, parlamentares não encontram o arcabouço institucional próprio para perseguir interesses particulares. Ao contrário, a melhor estratégia para obtenção de recursos visando retornos eleitorais é votar disciplinarmente (LIMONGI; FIGUEIREDO, 1998, p. 85).

Assim, o tamanho da bancada é de suma relevância para o exercício de atribuições, inclusive a presidência da mesa que cabe ao maior partido. Os líderes partidários, eleitos pelos seus iguais, possuem o direito de representá-los, bem como de controlar o fluxo dos trabalhos parlamentares. De acordo com Maria do Carmo Capello de Souza a relação do Estado com os partidos políticos no Brasil é uma relação historicamente deficitária composta por uma fragilidade institucional e uma terrível insistência em práticas clientelísticas. A desimportância dada aos partidos políticos no Brasil para a construção do projeto de nação e na articulação dos interesses básicos da nação e a concentração de poder no Executivo frente às políticas públicas fazem com que o Poder Legislativo tenha que pleitear espaços dentro da estrutura burocrática (LOUREIRO; OLIVIERI, 2010, p. 108).

Esta relação tensionada do Congresso, dos partidos políticos e da sociedade com a burocracia se arrasta no tempo, como destacam:

Talvez, seja mesmo possível falar da existência de uma inclinação favorável ao
poder da burocracia, por parte dos atores políticos, seja por fraqueza, isto é, por
incapacidade institucional e/ou política de contrapor-se às decisões do Executivo,
seja por interesses em criar formas particulares, clientelísticas ou corporativistas de
influir nas decisões da burocracia e/ou do Poder Executivo (LIMONGI;
FIGUEIREDO, 1998, p. 85).

${ }^{7}$ Dados obtidos pelo site do TSE no arquivo dos resultados das eleições. Disponível em: <http://www.tse.jus.br/eleicoes/estatisticas/repositorio-de-dados-eleitorais-1/repositorio-de-dadoseleitorais> Acessado em: 22. Jul. 2019.

Revista do Direito [ISSN 1982-9957]. Santa Cruz do Sul, n. 63, p. 163-185, jan. 2021. https://online.unisc.br/seer/index.php/direito/index 
Indo além, o texto constitucional assegura ao presidente a plena capacidade para criar e extinguir ministérios, órgãos da Administração Pública Federal, bem como prerrogativa para nomear cargos de livre provimento da administração federal. Assim, de acordo com a conveniência do Chefe do Executivo o mesmo possui a capacidade de interferência política sobre a estrutura burocrática. Assim, o direito de nomear cargos de confiança para o alto escalão burocrático, "[...] sem controles congressuais relevantes, dá ao chefe do Executivo maior liberdade para escolher nomes que estarão à frente da implementação da agenda de governo e, a depender de sua habilidade política, Ihe permite imprimir maior unidade de ação à sua coalizão" (LOPEZ; BUGARIN; BUGARIN, 2015, p.37).

A estrutura burocrática, portanto, vira moeda de troca para o contrato que o presidente prescinde firmar com os partidos que comporão a coalizão. Assim, os partidos que constituem a coalizão integram o governo, respondendo pelos sucesso ou insucesso da medidas adotas pelo Chefe do Executivo. Para Felix Lopez, Maurício Bugarin e Karina Bugarin "esta dinâmica remonta ao processo formativo de nossas instituições político-administrativas e sua importância se cristalizou na própria noção de confiança, que a linguagem comum associou aos cargos de livre provimento existentes da administração" (LOPEZ; BUGARIN, 2015, p. 35)

Outro ponto que envolve a disponibilidade da burocracia e o presidencialismo de coalizão é que as aproximações pluripartidárias costumam ser firmadas, após as eleições, sem prévio acordo a respeito das políticas públicas. "Estas características institucionais ampliam a possibilidade de haver divergências entre as preferências do presidente e seu partido, de um lado, e as preferências políticas dos partidos aliados, do outro" (BORGES; COÊLHO, 2015, p. 78). Nesse sentido, partidos políticos com ideologias antagônicas compõem a coalizão tendo como elo meramente a burocracia.

\section{CONSIDERAÇÕES FINAIS}

O Estado capitalista se reinventa usando o que e quem for preciso, tática facilmente perceptível em sua reformulação de Estado Liberal de Direito para Estado Social de Direito, Estado Fascista, Estado Democrático de Direito e, atualmente, segundo Rubens Casara, Estado PósDemocrático (CASARA, 2017). Desde a década de 1970 até os dias atuais, o neoliberalismo se apresenta como antonomásia; tática ofensiva e contrarrevolucionária do capital (contra o trabalho). Nesse sentido, a política neoliberal acaba sendo a reação - saída e solução - para as elites econômicas e políticas mundiais frente à crise estrutural e global do capitalismo tardio (PUELLOSOCARRÁS, 2008). A Administração Pública burocrática e gerencial no Brasil se insere nesse cenário neoliberal. Partindo dessa premissa, a pesquisa apresenta suas conclusões.

A ausência de uma burguesia nacional homogênea e industrial fez com que o Estado autoritário assumisse o papel de fiador do desenvolvimento industrial buscando um distanciamento do patrimonialismo. A burocracia racional-legal weberiana, portanto, chegou ao Brasil para atender políticas que colocassem o país nos trilhos da industrialização. É o Estado, novamente, sendo adequado pelas e para as elites. $O$ empresariado nacional e os burocratas assumem o protagonismo como agentes contrários a crise estrutural e global do capitalismo tardio. É o período em que os 
burocratas se agigantaram, pois passam a ser os executores das políticas públicas voltadas à industrialização.

O encastelamento do empresariado e da burocracia somado ao desgaste do regime militar fez com que os protagonistas iniciais do neoliberalismo fossem substituídos pelos Agentes Financeiros e os Rentistas. Mais uma vez, o Estado sendo readequado para atender os interesses da elite, agora internacional. A redemocratização e a aproximação internacional dos países ditos desenvolvidos, em especial após Consenso de Washington em 1989, fez com o Brasil passasse a adotar uma austera agenda de diminuição dos gastos públicos, disciplina fiscal, reforma tributária e a privatização. Tais medidas gestaram uma aguda crise administrativa e tributária no Brasil. Em um cenário totalmente complexo, no ano de 1995, a reforma gerencial passou a ser implantada prometendo a máxima delimitação do tamanho e a redefinição do papel regulador do Estado e a recuperação da governança frente à capacidade financeira, administrativa e política.

Desde então, quatro presidentes passaram pela Administração Pública do Poder Executivo Nacional. A literatura vem apontando para uma falha sequencial nas políticas de reforma administrativa. Há problema de performance que, consecutivamente, tem levado com que cada novo presidente tente criar fórmulas simples para um problema secular. Em resumo, como aduz Rezende (2002, p. 51) o "clientelismo, corrupção, reduzida eficiência, reduzido grau de profissionalismo, elevados gastos e déficits no setor público, bem como outros males burocráticos" permanecem como marcas da Administração Pública.

A baixa performance das reformas administrativas dificulta a tensionada relação entre a burocracia e o sistema político no presidencialismo de coalizão adotado no Brasil. É bem verdade que a politização da burocracia não pode ser vista a priori como algo ruim. Entretanto, os séculos de burocracia colonial e patrimonialista brasileira fazem com que, tal estratégia, fortemente utilizada pelo presidencialismo de coalizão, seja rechaçada socialmente. Ainda mais quando partidos políticos com agendas tão antagônicas praticam a coalizão meramente para alçar espaço na burocracia brasileira.

Ademais, restou claro ao leitor que o artigo buscou ir além do debate a respeito da governabilidade gestada pelo poder de agenda e controle discricionário sobre cargos e orçamento. Até porque, a literatura sustenta que tal prática garante ao presidente tanto o status de maior propositor de projetos de lei quanto índices altíssimos de aprovação dos mesmos. A pesquisa focou em mostrar os desafios ainda existentes por trás da fórmula da coalizão.

É nesse sentido que faz-se relevante debater os partidos políticos, o papel dos líderes partidários, a relação com os cargos de nomeações e o orçamento público. Como demonstrado na pesquisa as regras eleitorais, a estrutura federativa e a centralização da burocracia e do orçamento no Poder Executivo ao mesmo tempo que o torna o grande detentor da burocracia e do orçamento público, na via inversa, o faz dependente da relação com os partidos políticos e, em especial, com seus líderes partidários. Esta estrutura vem estimulando as estratégias localistas, distributivas e personalistas. Assumir o papel de interlocutor do Governo Federal frente a burocracia pública e seu orçamento em tempos de políticas estruturantes é uma forma de garantir espaços de poder e projeção aos políticos e seus partidos. É preciso modernizar o presidencialismo de coalizão e sua relação com os partidos, os líderes partidários e a burocracia pública. 
O salto de 18 partidos em 1988 para 27 em 2014 na Câmara dos Deputados e o aumento da quantidade de partidos para construção da maioria simples e maioria qualificada mostram a necessidade de um debate mais intenso a respeito da politização da burocracia, pois a cada ano a coalizão demanda mais ministérios e cargos para que se recepcione maior número de partidos.

\section{REFERÊNCIAS}

ABRÚCIO, Fernando Luiz. Três agendas, seus resultados e um desafio: balanços recente da Administração Pública Federal Brasileira. Revista de Ciências Sociais da PUC - RIO. RJ, Dossiê Especial, p. 119-142 Segundo semester de 2011.

; PEDROTI, Paula; VINICIUS PÓ, Marcos. A formação da burocracia brasileira: a trajetória e o significado das reformas administrativas. In: LOUREIRO, Maria Rita; ABRUCIO, Fernando Luiz; PACHECO, Regina (Orgs.). Burocracia e política no Brasil: Desafios para a ordem democrática no século XXI. RJ: FGV, 2010, p. 27-72.

. Os Barões da Federação. Revista Lua Nova, SP, N. 33, 165-190, 1994.

AMORIM NETO, O. Presidencialismo e Governabilidade nas Américas. RJ: FGV; Konrad Adenauer Stiffung, 2006.

BATISTA, Mariana. O poder no Executivo: uma análise do papel da presidência e dos ministérios no presidencialismo de coalizão brasileiro (1995-2010). Opinião Pública, v.19, n.2, set./dez., p.449-473, 2013.

BEETHAM, D. Bureaucracy. Buckingham: Open University Press, 1996.

BORGES, André; COÊLHO, Denilson Bandeira. O preenchimento de cargos da burocracia pública federal no presidencialismo de coalizão brasileiro: Análise Comparada de dois Ministérios - Ciência e Tecnologia e Integração Nacional. In: LOPES, Feliz Garcia (Org.). Cargos de confiança no presidencialismo de coalizão brasileiro. Brasílea: IPEA, p. 71-106, 2015.

BRASIL. Decreto de 7 de março de 2017. Disponível em: < http://www.planalto.gov.br/ccivil_03/_ato2015-2018/2017/dsn/Dsn14451.htm> Acessado em 20. Jun. 2019.

Decreto no 9.262, de 9 de janeiro de 2018. Disponível em:<http://www.planalto.gov.br/ccivil_03/_ato2015-2018/2018/decreto/D9262.htm> acessado em: 02. Jul. 2019. 
Decreto-Lei no 200, de 25 de fevereiro de 1967. Disponível em: <http://www.planalto.gov.br/ccivil_03/decreto-lei/del0200.htm> acessado em: 08. Jun. 2019.

Decreto-Lei no579, de 30 de julho de 1938. Disponível em: <https://www2.camara.leg.br/legin/fed/declei/1930-1939/decreto-lei-579-30-julho-1938-350919publicacaooriginal-126972-pe.html> acessado em: 08. Jun. 2019.

Lei no 13.726, de 08 de outubro de 2018. Disponível em: <http://www.planalto.gov.br/ccivil_03/_ato2015-2018/2018/Lei/L13726.htm> Acessado em: 05. Jul. 2019.

Medida Provisória oㅡ 726, de 12 de maio de 2016. Disponível em: < http://www.planalto.gov.br/ccivil_03/_Ato2015-2018/2016/Mpv/mpv726.htm> Acessado em: 22. jun. 2019.

. Plano Diretor da Reforma do Estado, 1995.

BRESSER PEREIRA, Luiz Carlos. Reforma do Estado para a Cidadania: A Reforma Gerencial Brasileira na Perspectiva Internacional. SP: Editora 34, 1998.

Burocracia Pública e Estado no Brasil. Revista Eletrônica sobre a Reforma do Estado. Salvador, N. 11 - Set/Out/Nov, p. 1 - 65, 2007.

Burocracia pública na construção do Brasil. Disponível em: < http://www.bresserpereira.org.br/BOOKS/Burocracia_Publica_construcao_Brasil.pdf> aceassado em: 05. Jul. 2019.

. Da administração pública burocrática à gerencial. In: BRESSER-PEREIRA, Luiz Carlos; SPINK, Peter Kevin (Org.). Reforma do Estado e administração pública gerencial. RJ: FGV, 1999.

. Gestão do setor público: estratégia e estrutura para um novo Estado. RJ: FGV, 2006.

Burocracia Pública e Reforma Gerencial. SP. 2007. Disponível em: < http://www.bresserpereira.org.br/papers/2007/BurocraciaPublicaeReformaGerencial.pdf>. Acesso em: 09 de jul. 2019

CASARA, Rubens R R. Estado Pós-Democrático: neo-obscurantismo e gestão dos indesejáveis. RJ: Civilização Brasileira, 2017. 
CASTOR, Belmiro Valverde Jobim. O Brasil não é para amadores: Estado, Governo e Burocracia na terra do jeitinho. 2. ed. Curitiba: Travessa Dos Editores, 2004.

FAORO, Raymundo. Os donos do poder: formação do patronato político brasileiro. SP: Globo, 2001.

França. Declaração dos Direitos do Homem e do Cidadão. França, 1789. Disponível em: <http://pfdc.pgr.mpf.mp.br/atuacao-e-conteudos-de-apoio/legislacao/direitoshumanos/declar_dir_homem_cidadao.pdf> Acessado em: 10. Jul. 2019.

FREITAS, Andréa Marcondes. O presidencialismo de coalizão. (Tese) Doutorado em Ciência Política. Faculdade de Filosfia, Letras e Ciências Humanas, Universidade de São Paulo. São Paulo, p. 21, 2013.

FREYRE, Gilberto. Casa-Grande e Senzala. RJ: Editora Record, 1992.

GABARDO, Emerson. O Jardim e a Praça Para Além do Bem e do Mal: uma antítese ao critério de subsidiariedade como determinante dos fins do Estado social. (TESE) Doutorado em Direito do Estado, Setor de Ciências Jurídicas da Universidade Federal do Paraná, 2009.

Princípio constitucional da eficiência administrativa. SP: Dialética, 2002.

GORENDER, Jacob. A burguesia brasileira. SP: Brasiliense, 2004.

HOBSBAWM, Eric J. A Era das Revoluções. RJ/SP: Paz e Terra, 2017.

HOLANDA, Sérgio Buarque. Raízes do Brasil. SP: Companhia das Letras, 2009.

LIMONGI, Fernando. Presidencialismo, coalizão partidária e processo decisório. Revista Novos Estudos. N. 76, p. 17-41, 2006.

; FIGUEIREDO, Argelina. Bases institucionais do presidencialismo de coalizão. Revista Lua Nova. SP, n. 44, p. 82-106, 1998.

LINDNER, Julia. Lewandowski diz que impeachment foi "tropeço" na democracia. Exame. Disponível em: $\quad$ <https://exame.abril.com.br/brasil/lewandowski-diz-que-impeachment-foi-tropeco-nademocracia/> Acessado em: 04. Jun. 2017.

LOPEZ, Felix Garcia; BUGARIN, Maurício; BUGARIN, Karina. Mudanças político-partidárias e rotatividade dos cargos de confiança (1999-2013). In: LOPEZ, Felix Garcia. Cargos de confiança no presidencialismo de coalizão brasileiro. Brasília: IPEA, 2015, p.34-58. 
; PRAÇA, Sérgio. Cargos de confiança, partidos politicos e burocracia federal. Revista IberoAmericana de estudos legislativos. RG: FGV, N. 4, mai, p. 33-42, 2015.

LOUREIRO, Maria Rita; OLIVERI, Cecília; MARTES, Ana Cristina. Burocratas, partidos políticos e grupos de interesse: o debate sobre política e burocracia no Brasil. In: LOUREIRO, Maria Rita Garcia; ABRUCIO, Luiz Fernando; ABRUCIO, Regina Silvia Pacheco. Burocracia e política no Brasil: desafios para a ordem democrática no século XXI. RJ: FGV, 2010.

MARTUSCELLI, Danilo Enrico. "A ideologia do "presidencialismo de coalizão". Revista Lutas Sociais. SP, n24, 1ํㅗ Sem, p. 60-69, 2010.

MARX, Karl. Crítica a filosofa do direito de Hegel. Lisboa: Editorial Estampa, 1983.

; ENGELS, Friedrich. Manifesto do Partido Comunista. SP: Penguin Classics, 2012.

MISOCZKY, Maria Ceci; ABDALA, Paulo Ricardo; DAMBORIARENA, Luiz. A trajetória ininterrupta da reforma do aparelho de Estado no Brasil: continuidades nos marcos do neoliberalismo e do gerencialismo. Revista Administração Pública e Gestão Social, 9 (3), Jul - Set, p. 184-193, 2017, p. 192.

MULLER, Wolfgang; STROM, Kaare. Policy, Office or Votes? How political parties in Western Europe make hard decisions. NY : Cambridge University Press, 1999.

PESSOA, Robertônio Santos. Disputa Política e agenda administrativa: do governo FHC à gestão Lula-Dilma. Revista Arquivo Jurídico. Piauí: UFPI, v. 2, n. 01, p. 61-81, 2015.

PRONER, Carol; CITTADINO, Gisele; TENEBAL; Marcio; RAMOS FILHO, Wilson. A resistência ao golpe de 2016. Bauru: Canal 6, 2016.

Puello-Socarrás, J. F. Nueva Gramática del Neoliberalismo. Itinerarios teóricos, trayectorias intelectuales, claves ideológicas. Bogotá: Universidad Nacional de Colombia, Facultad de Derecho, Ciencias Políticas y Sociales, 2008.

REZENDE, Flávio da Cunha. O dilema do controle e a falha sequencial nas reformas gerenciais. Revista do Serviço Público. Revista do Serviço Público. Ano 53, N. 3, Jul - Set, p. 50-74, 2002.

WEBER, Max. A Ciência como Vocação. SP: Editora Martin Claret, 2002. 
- Economia e sociedade: fundamentos da sociologia compreensiva. Brasília: UNB; SP: Impressão Oficial do Estado de SP, 1999.

. Parlamentarismo e Governo numa Alemanha reconstruída. SP: Nova Cultura, 1997.

Revista do Direito [ISSN 1982-9957]. Santa Cruz do Sul, n. 63, p. 163-185, jan. 2021. https://online.unisc.br/seer/index.php/direito/index 